\title{
Ectopic expression of mitochondrial gamma carbonic anhydrase 2 causes male sterility by anther indehiscence
}

\author{
Fernando Villarreal · Victoria Martín · Alejandro Colaneri · \\ Nahuel González-Schain · Mariano Perales · Mariana Martín · \\ Cristina Lombardo · Hans-Peter Braun · Carlos Bartoli · \\ Eduardo Zabaleta
}

Received: 25 July 2008/Accepted: 15 March 2009/Published online: 27 March 2009

(C) Springer Science+Business Media B.V. 2009

\begin{abstract}
Plant mitochondria include gamma-type carbonic anhydrases $(\gamma \mathrm{CAs})$ of unknown function. In Arabidopsis, the $\gamma$ CAs form a gene family of five members which all are attached to the NADH dehydrogenase complex (complex I) of the respiratory chain. Here we report a functional analysis of gamma carbonic anhydrase 2 (CA2). The gene encoding CA2 is constitutively expressed in all plant organs investigated but it is ten fold induced in flowers, particularly in tapetal tissue. Ectopic expression of CA2 in Arabidopsis causes male sterility in transgenic plants. In normal anther development, secondary thickenings of the endothecial cell wall cause anthers to open upon dehydration. Histological analyses revealed that abnormal secondary thickening prevents anther opening in $35 \mathrm{~S}:: \mathrm{CA} 2$ transgenic plants. CA2 abundance in transgenic plants is increased 2-3 fold compared to wild-type plants as revealed by Western blotting analyses. Moreover, abundance of other members of the CA family, termed CA3 and CAL2, is increased in transgenic plants. Oxygen uptake
\end{abstract}

Gene bank accession number: AY085025 (At1g47260).

F. Villarreal · V. Martín · A. Colaneri · N. González-Schain ·

M. Perales · M. Martín · C. Lombardo · E. Zabaleta $(\bowtie)$

Instituto de Investigaciones Biológicas, IIB, Facultad de Cs.

Exactas y Naturales, UNMdP-CONICET, C.C. 1245 ,

7600 Mar del Plata, Argentina

e-mail: ezabalet@mdp.edu.ar

H.-P. Braun

Institut für Pflanzengenetik, Universität Hannover, Herrenhäuser

Str. 2, 30419 Hannover, Germany

C. Bartoli

Instituto de Fisiología Vegetal, Facultades de Ciencias Naturales y Ciencias Agrarias y Forestales, Universidad Nacional de La

Plata, Diagonal 113 no. 495, 1900 La Plata, Argentina measurements revealed that respiration in transgenic plants is mainly based on NADH reduction by the alternative NADH dehydrogenases present in plant mitochondria. Furthermore, the formation of reactive oxygen species (ROS) is very low in transgenic plants. We propose that reduction in ROS inhibits $\mathrm{H}_{2} \mathrm{O}_{2}$ dependent lignin polymerization in $\mathrm{CA} 2$ over-expressing plants, thereby causing male sterility.

Keywords Gamma carbonic anhydrases - Mitochondria . Reactive oxigen species - Anther - Arabidopsis thaliana

\section{Introduction}

Carbonic anhydrase (CA; carbonate dehydratase, carbonate hydro-lyase, EC 4.2.1.1) is a zinc-containing enzyme which catalyzes the interconversion of $\mathrm{CO}_{2}$ and $\mathrm{HCO}_{3}{ }^{-}$. Carbonic anhydrases are divided into three distinct classes $(\alpha, \beta$, and $\gamma)$ which evolved independently and have no sequence homology (Hewett-Emmett 2000). These enzymes are ubiquitous in highly evolved organisms from Eukarya domain and are also prevalent in Archaea and Bacteria domains. This occurrence of CAs underlines the importance of these enzymes in many organisms (Smith et al. 1999 and references there in). In plants and unicellular green algae, beta-type CAs are known to be essential for photosynthetic $\mathrm{CO}_{2}$ fixation (Badger and Price 1994). It was recently discovered a new group of CAs in plant mitochondria. These proteins strongly resemble a gammatype carbonic anhydrase from the Archeon Methanosarcina termophila (Parisi et al. 2004; Perales et al. 2004). Five structurally related mitochondrial gamma-type carbonic anhydrases ( $\gamma \mathrm{CAs})$ are present in Arabidopsis mitochondria which are termed CA1, CA2, CA3, CAL1, and CAL2 
(CAL stands for "carbonic anhydrase like"; Perales et al. 2004). These five enzymes are attached to mitochondrial complex I and they form an extra domain characteristic of this respiratory enzyme complex in plants (Sunderhaus et al. 2006). An Arabidopsis null mutant for CA2 shows an $80 \%$ reduction of complex I levels. Mutant plants have a normal growth rate and fertility, but mutant cell cultures exhibit defects in respiration. It was thus suggested that CA2 is important for complex I assembly (Perales et al. 2005). However, the actual physiological role of the $\gamma \mathrm{CAs}$ is unclear. It was recently proposed that they are important in a context of an inner-cellular $\mathrm{CO}_{2}$ transfer mechanism from mitochondria to chloroplasts, to recycle photorespiratory $\mathrm{CO}_{2}$ for photosynthesis (Braun and Zabaleta 2007). Recent studies with maize indicate that these proteins are also present in C4 plants (Peters et al. 2008). However, carbonic anhydrase activity could not be measured for any of the plant mitochondrial CAs, so far. Indeed, the only $\gamma \mathrm{CA}$ with measurable CA activity is CAM from $M$. thermophila (Alber and Ferry 1994; Zimmerman and Ferry 2008).

In Arabidopsis thaliana, as in most flowering plant species, the anther wall comprises four cell layers: the epidermis, endothecium, middle layer, and tapetum (Dawson et al. 1993). Anther dehiscence is a multiple-step process. In the first place, the lytic opening of a longitudinal line of weakness in the epidermis, which is known as the stomium, occurs. Afterwards, anther wall retracts to widen the stomium, allowing pollen release. During microspore maturation, cellulose and lignified thickenings are deposited in the endothecium (Dawson et al. 1999). The cells of the stomium are then enzymatically lysed (Goldberg et al. 1993). The endothecium is thought to be critical in generating the mechanical forces required for dehiscence. First, swelling of the endothecium cells provides an inwardly directed force. This force causes the rupture of the weakened stomium. Then, desiccation of the endothecium causes differential shrinkage of thickened and unthickened parts of the cell wall, resulting in an outwardly bending force which leads to the retraction of the anther wall and to the full opening of the stomium (Keijzer 1987; Bonner and Dickinson 1989). Lignin is an important structural component of the cell wall. The final polymerization steps of lignin biosynthesis take place after the activation of monolignols to free radicals. This activation is mediated by peroxidase $+\mathrm{H}_{2} \mathrm{O}_{2}$ and/or oxidase (laccase) $+\mathrm{O}_{2}$ followed by non-enzymatic coupling of monolignol radicals to form the polymer, lignin (Boerjan et al. 2003; Ralph et al. 2004). For the secondary thickening in anthers, lignin is the main compound (Kawasaki et al. 2006) and its polymerization is dependent on $\mathrm{H}_{2} \mathrm{O}_{2}$ levels. Ascorbic acid (AsA) interferes with the peroxidasemediated oxidation of phenolics by reducing phenolic radicals back to the original phenolics, thereby scavenging $\mathrm{H}_{2} \mathrm{O}_{2}$ (Takahama 1993a, b; Otter and Polle 1994; Sánchez et al. 1997). Therefore, a negative correlation between AsA and $\mathrm{H}_{2} \mathrm{O}_{2}$ contents has been observed (Pedreira et al. 2004; Kärkönen and Fry 2006).

In this report, to further investigate the physiological role of putative mitochondrial gamma carbonic anhydrases in plants, we analyzed the phenotypic and biochemical consequences of ectopic over-expression of one of the plant $\gamma$ CAs, CA2 in transgenic A. thaliana. A high proportion of $35 \mathrm{~S}: \mathrm{CA} 2$ overexpressing Arabidopsis plants show a severe male sterile phenotype caused by a defect of secondary thickening in the anther endothecium and subsequent failure of anther dehiscence. Analyses of physiological parameters indicate that respiration is affected in 35S::CA2 plants mainly at Complex I level. In addition, normal reactive oxygen species (ROS) burst prior to anther dehiscence is undetectable, although ascorbate and glutathione content is nearly normal. It is therefore suggested that ectopic over-expression of CA2 impairs ROS production in mitochondria which affects mainly the $\mathrm{H}_{2} \mathrm{O}_{2}$-dependent polymerization pathway of lignin in anther development and consequently, causes a male sterile phenotype.

\section{Materials and methods}

\section{Plant material}

Arabidopsis thaliana, var. Columbia (Col-0) were grown in a Greenhouse with temperature $\left(22^{\circ} \mathrm{C}\right)$ and humidity $(50$ $70 \%$ ) controlled and a photoperiod of $16 \mathrm{~h}$ light/ $8 \mathrm{~h}$ dark. For transformation, the floral dip method was used (Clough and Bent 1998) with the Agrobacterium tumefaciens strain GV3101.

Ligth and confocal microscopy

Inflorescences were fixed in FAA (ethanol:destilled water:phormol:acetic acid, 10:7:2:1, respectively). Afterwards fixed influorescences were dehydrated and included in Paraplast (Sigma) according to Ruzin (1999). Finally, the samples were mounted and cut using a rotary microtome. The sections were stained with Toluidin Blue $\mathrm{O}$ (TBO). They were examined by a bright field microscopy in a Nikon Eclipse E 2000 microscope (Tokyo). Images were captured using a Coolpix 990 digital camera attached to the microscope. Confocal microscopy was carried out with the BX61-FV300 microscope (Olympus Optical, Tokyo, Japan) using an ethidium bromide/acridine orange stain according to Yang et al. (2007). The microscopy was equipped with an argon/helium-neon-G laser with 
excitation/emission at $488 / 515 \mathrm{~nm}$. Images from the anthers were analysed by using Image J 1.36 software.

Protein analyses

Protein extracts were performed following standard techniques (Sambrook and Russell 2001). 1D SDS-PAGE was carried out according to Schägger and von Jagow (1987). Gels were stained using the Coomassie-colloidal procedure (Neuhoff et al. 1990). Anti-CA antibody was generated as described previously (Perales et al. 2005). This antibody recognizes the five gamma-type CA from Arabidopsis. For immunoblotting, gels were blotted onto PVDF membranes (GE Healthcare). Blots were incubated with antibodies following standard techniques (Sambrook and Russell 2001). Blots were washed three times with PBS $1 \times$ and incubated $1 \mathrm{~h}$ at room temperature in the dark with secondary antibodies conjugated with Cy5 (GE Healthcare) washed and scanned in Storm860 (GE Healthcare). Quantification of bands was performed by using ImageQuaNT software (GE Healthcare).

\section{DNA and RNA techniques}

Full-length cDNA corresponding to CA2 gene (At1g47260) was amplified by RT-PCR using the following primers: 5'-ATCTCGAGATGGGAACCCTAGGCA-3' and 5'-GCCTCGAGTCAGTTCACATTAGAA-3'. The corresponding fragment was separated by agarose gels, purified and cloned into pGEM-T vector (Promega) and fully sequenced.

For plant transformation, the coding region of CA2 was amplified 5'-GTTCTAGAATGGGAACCCTAGGA-3' as forward primer and 5'-GACTCGAGTTAGAAGTACT GAG- $3^{\prime}$ as reverse primer. Alternatively, primer $5^{\prime}$-AA ATCTAGATTACTTGTCATCGTCGTCCTTGTAGTCGA AGTACTGAGTAGACGGAACCTTGG-3' was used as reverse primer to introduce a FLAG tag to CA2. This region was fully sequenced and subcloned into the vector pCHF3 producing pCHCA2 or pCHCA2-FLAG. The vector contains the CaMV $35 \mathrm{~S}$ full promoter, the RBCS terminator from pea, and confers kanamycin resistance for selection in plants. This new plasmid was introduced into A. tumefaciens GV3101 by electroporation and the presence of the plasmid was analyzed by colony-PCR. Positives colonies were used to transform plants by floral dip method (Bechtold and Pelletier 1998). Seeds obtained from the transformed plants were plated on MS with Gamborg's vitamins medium (Duchefa, Netherlands) supplemented with $50 \mu \mathrm{g} / \mathrm{ml}$ Kanamycin (ICN Biomedicals, Aurora, $\mathrm{OH}$ ) to select transgenic plants.

Semiquantitative RT-PCRs were performed on total RNA. Total RNA was extracted from leaves, roots, young and mature flowers and cell suspension, by using TrizOL reagent (Invitrogen). Reverse transcription coupled to polymerase chain reaction (RT-PCR) was conducted using $1 \mu \mathrm{g}$ of total RNA. Total cDNA was obtained using random hexamers (Promega). Primers used to amplify specifically mRNA transcripts were: 5'-TACTCGAGAT GGGAACCCTAGGCA- $3^{\prime}$ and $5^{\prime}$-GCCTCGAGTCAGTT CACATTAGAA-3' for $C A 1,5^{\prime}$-TTGGATCCATCTCGC ACAGATTC-3' and 5'-GACTCGAGTTAGAAGTACT GAG-3' for $C A 2,5^{\prime}$-GCCTCGAGATGAATGTTTTTG AC-3' and 5'-ATCTCGAGTCAAGCTGCTTTTGGT-3' for $C A 3,5^{\prime}-3^{\prime}$ CGTCGACGGATCTTGTGAA and 5'-GAG

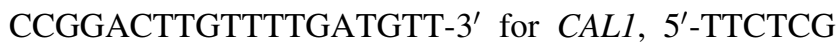
AGATGGCGACTTCGTTA-3' and 5'-TTCT CGAGACT AGATGGCGATTCC-3' for CAL2. As a control, a fragment of $651 \mathrm{bp}$ from the transcript corresponding to the gene encoding ACT2 mRNA from Arabidopsis was amplified with two specific oligonucleotides: $5^{\prime}$-AATCTC CGGCGACTTGACAG-3' and 5'-AAACCCTCGTAGAT TGGCACAG-3'. Aliquots were removed from the reaction mixture after $8,12,16,20,24$, and 35 cycles of PCR (amplifications were in the exponential range between cycles 12 and 20), separated on agarose gel stained with SybrGold (Molecular Probes). Signal intensities were determined and quantified using a scanner Storm 680 (GE, Healthcare). Values from the exponential range of amplification were compared.

In situ hybridization

For in situ hybridization floral buds, flowers and fruits at different stages were fixed and embedded in paraffin. Ten $\mu \mathrm{m}$ sections were hybridized as described elsewhere (Meyerowitz 1987). Digoxigenin-labeled RNA probes were synthesized by in vitro transcription. The specific $3^{\prime}$ end of $C A 2$ was amplified using primers $5^{\prime}$-ACCTC GAGTGGTTGCTGCTGGT- $3^{\prime}$ and 5'-TCTCTTGACCTT CCAGAGAATCA-3' and cloned into pBluescript (SK-). Antisense and sense (control) transcripts were generated by using either the T3 or T7 RNA polymerase (Promega). The transcripts were partially hydrolysed by incubation at $60^{\circ} \mathrm{C}$ in $0.1 \mathrm{M} \mathrm{Na}_{2} \mathrm{CO}_{3} \cdot \mathrm{NaHCO}_{3}$ buffer, $\mathrm{pH} 10.2$ for $45 \mathrm{~min}$. Immunological detection of digoxigenin was performed as described (Boehringer Mannheim, Nonradioactive in situ hybridization, Application Manual, 1996).

Immuno-histochemical analyses

Flower sections from Col-0 and 35S::CA2 were deparaffined and rehydrated in successive alcohol solutions. Finally, they were blocked in $3 \%$ bovine serum albumin in PBS $1 \times$ buffer for $30 \mathrm{~min}$ at room temperature. After washing in PBS-Tween $200.05 \%$, Anti-CA2 antibody, 
which recognizes CA2 specifically (Perales et al. 2005), was added and incubated for $2 \mathrm{~h}$ in humidity chamber (3\% BSA-PBS was used as negative control). The slides were washed three times in PBS-Tween 20, and subsequently incubated for $1 \mathrm{~h}$ with secondary antibody conjugated to alkaline phosphatase (Sigma). After washing in PBSTween 20, the reaction with NBT-BCiP was developed, followed by microscopy and stopped with buffer TE. Control sections were processed without anti-CA2 antibody.

In situ $\beta$-glucoronidase activity and lignin detection

In situ $\beta$-glucoronidase activity was analyzed in several tissues of CA2promoter::uidA transgenic plants, as described in Zabaleta et al. (1998).

Lignin detection by Ethidium bromide staining and confocal microscopy was performed as described in Yang et al. (2007).

In situ determination of reactive oxygen species

For detection of ROS in plant tissues, inflorescences and leaves of Arabidopsis plants were incubated in light with a solution $0.5 \mathrm{mg} / \mathrm{ml}$ of $3,3^{\prime}$-diaminobenzidine (DAB) in $50 \mathrm{mM}$ sodium acetate buffer ( $\mathrm{pH} 5,4)$, or $0.5 \mathrm{mg} / \mathrm{ml}$ of Nitrobluetetrazolium (NBT) in buffer $25 \mathrm{mM}$ HEPES $\mathrm{pH}$ 7 , for $2 \mathrm{~h}$ at $25^{\circ} \mathrm{C}$. Afterwards, the solution was removed and tissues were decolorated with ethanol over night. Images were taken with a binocular SMZ800 (Nikon) and a CoolSnap Pro camera (MediaCybernetics, TX).

Determination of antioxidants

Ascorbic acid levels (total and reduced) and glutathione levels (total and reduced) from Arabidopsis tissues were measured as described previously (Bartoli et al. 2006; Griffith 1980).

\section{Oxygen consumption assay}

Oxygen consumption assay was performed as described in Bartoli et al. (2006). Respiration of detached leaves was monitored using the LD2/3 leaf disc electrode (Hansatech, UK). Complex I pathway was inhibited with $40 \mu \mathrm{M}$ rotenone. To assess the maximum capacity of the AOX pathway, the cytochrome $c$ pathway was inhibited with $1 \mathrm{mM} \mathrm{KCN}$. Leaves were immersed for $3 \mathrm{~h}$ prior to assay, in the buffer containing these respiratory inhibitors together with a surfactant agent $(0.05 \%$ Tween-20) to allow penetration, under low light $\left(10-20 \mu \mathrm{mol} \mathrm{m}^{-2} \mathrm{~s}^{-1}\right)$. The leaves were then dried and placed in the oxygen electrode chamber. Then respiration was measured.

\section{Results}

At $\gamma$ CAs are differentially expressed throughout the plant

Semiquantitative RT-PCR analyses were performed to evaluate the expression pattern of Arabidopsis $\gamma C A$ genes. $C A 2$ transcripts are weakly expressed in roots and leaves but expression is enhanced about ten times in flower tissues (Fig. 1A). This fact could be explained in part because of the increase in the number of mitochondria per cell in flowers tissues (Zabaleta et al. 1998). To further analyze the expression pattern, in situ hybridization analyses were performed. As shown by Fig. 1B, the expression seen in flowers is mainly due to an augmentation of transcript levels in anthers, particularly in tapetal cell layer, inflorescence (IM) and floral meristems (FM).

Expression of CA2 was further investigated using the GUS reporter gene expressed under the control of 2,000 bp of the putative $C A 2$ promoter. The obtained data nicely correlate with RT-PCR and RNA in situ experiments. Expression in anthers starts very early during flower development and in seed development as reported before for the complex I subunits (Fig. 1C, D and E; Zabaleta et al. 1998).

35S::CA2 plants show a severe male sterile phenotype

Ectopic expression of this protein in transgenic Arabidopsis plants causes a severe male sterile (ms) phenotype. Eighteen of twenty-one T0 35S::CA2 plants showed this phenotype, while the remaining plants presented wild type phenotype. In previous transformation experiments using 35S::CA2-FLAG or 35S::CA2-GFP (Parisi et al. 2004 and data not shown), similar phenotypes were observed. Kanamycin resistant ms plants are continuously growing for more than 8 months and multiple bolts arise from the rosette. All of the ms 35S::CA2 plants are flowering 67 days earlier than wild type plants (Fig. 2F). The first bolts develop male sterile flowers containing anthers unable to undergo dehiscence (Fig. 2C, D). However, fertile flowers appear sometimes in further bolts. Male sterile flowers could be pollinated and fertilized by wild type pollen grains and, in some cases, are able to be manually selfed. Eventually, a small proportion of nearly normal siliques successfully develop in overexpressing ms plants. Seeds resulting from these crosses are bigger than wild type ones (Fig. 2G), and plate-grown seedlings developed larger primary roots (Fig. 2E). A nearly $65 \%$ of progeny $(13 \pm 1$ of $19 \pm 2$ ) obtained from these transgenic plants show the same phenotype. Sterility was shown to be stable under several environmental conditions.

A correlation between over-expression of $C A 2$ transcript and phenotype was performed and $100 \%$ of ms plants over- 

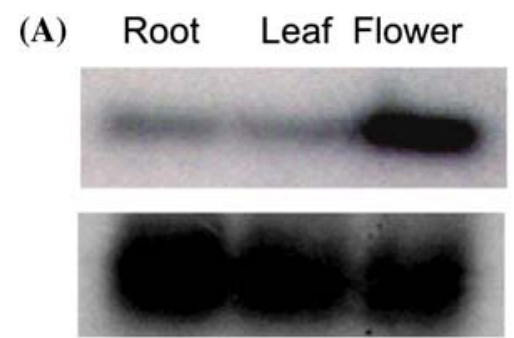

ACTIN2

(B)
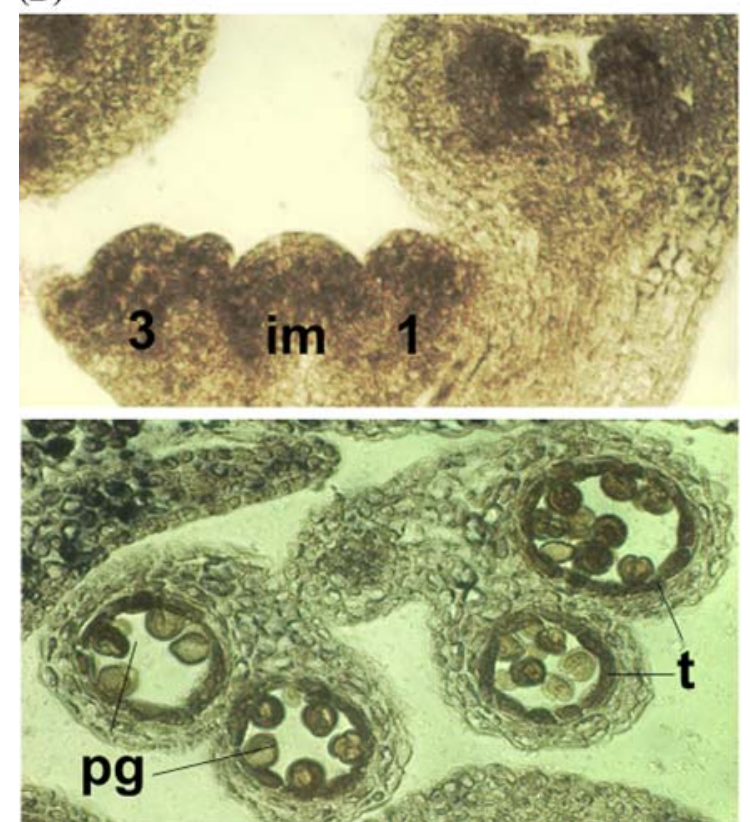
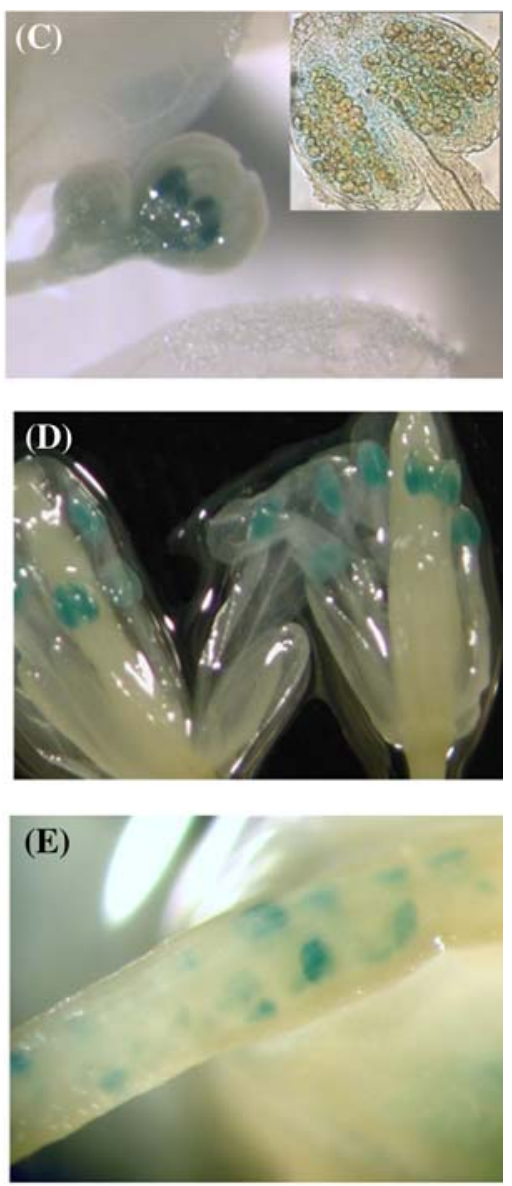

Fig. 1 Gamma carbonic anhydrase 2 (CA2) is expressed strongly in anthers. The expression pattern of CA2 was studied by A semiquantitative RT-PCR. Total RNA from root, leaf, and flower was extracted. Using specific primers, a cDNA fragment corresponding to $C A 2$ mRNA was amplified by 16 cycles (exponential phase) and separated by electrophoresis on agarose gels. Samples containing Sybr Gold were quantified. ACTIN 2 gene is shown as loading control. B In situ hybridization Top Longitudinal section showing inflorescence meristem hybridized with a CA2 antisense probe labeled with digoxigenin UTP and revealed with NBT/BCiP. Inflorescence

expressed the transcript, while plants which did not, showed a phenotype undistinguishable from wild type plants. In most of the $35 \mathrm{~S}:$ :CA2 plants showing wild type phenotype, CA2 transcript was indeed silenced which correlates with the observed phenotype of $c a 2$ null mutant plants (Fig. 3; Perales et al. 2005).

Anther development is altered in $35 \mathrm{~S}:: \mathrm{CA} 2$ plants but pollen develop nearly normal

Normal anther development comprises several stages from differentiation of four layers of different cell identity to the final anther dehiscence. At stage 8 of flower development, the degeneration of tapetal cell layer occurs (Fig. 4A top). At stage 11, thickening of endothecium by pollen mitosis I meristem (im), and developing flowers in stages 1 and 3. Bottom Transversal section of an anther at stage 10 ( $p g$ pollen grains; t tapetum). C-E GUS activity staining with X-Gluc. Arabidopsis were transformed with a construct containing 2,000 bp upstream the ATG of $C A 2$ gene fused to uidA gene ( $\beta$-glucuronidase-GUS). Transgenic plants were selected by resistant to Kanamycin. X-Gluc staining is detected as a dark blue precipitate; $\mathbf{C}$ stage 10 flower (inset, microscopic detail of anther showing tapetum staining); D stage 12 flowers; $\mathbf{E}$ carpel

starts, having its maximal by pollen mitosis II. Secondary thickening occurs in the endothecium as bands of striated spring-like thickening which is composed of cellulose and lignin (Fig. 4A center). This thickening is necessary to create the shearing force required for the final anther dehiscence through the stomium. In the $35 \mathrm{~S}:: \mathrm{CA} 2$ anthers, no secondary thickening is observed in the anther endothecium (Fig. 4 center-note the abnormal endothecium development and absence of fibrous bands in 35S:CA2 anthers), although other tissues in the transgenic plant undergo normal secondary thickening. This lack of strengthening of the endothecium means that as the anther dehydrates, the endothecium layer distorts and thus shearing forces do not take place. Therefore the anther fails to open avoiding pollen grains to release. In normal 

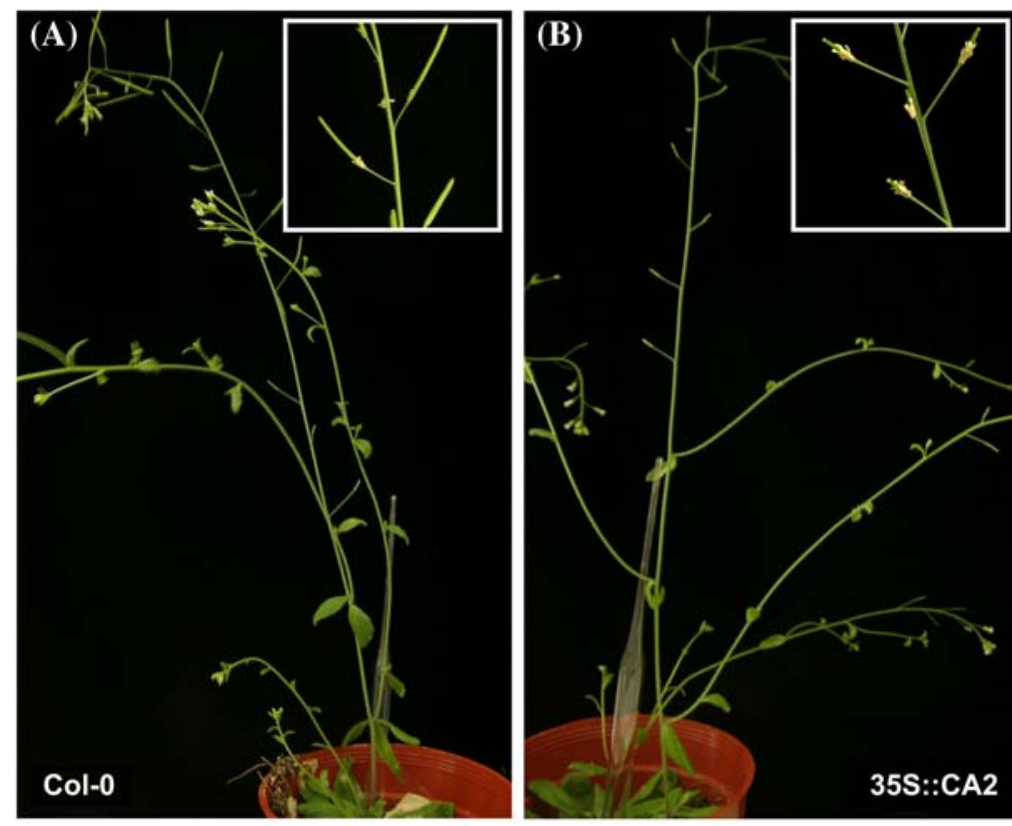

Col-0
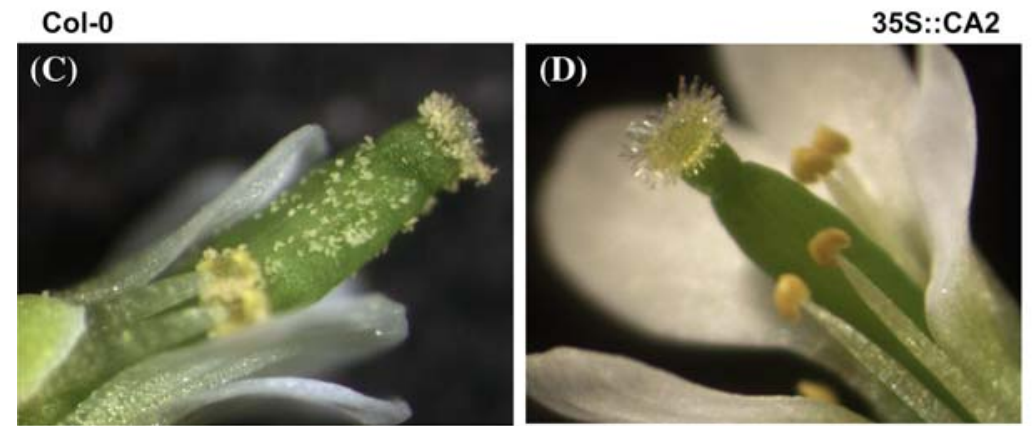
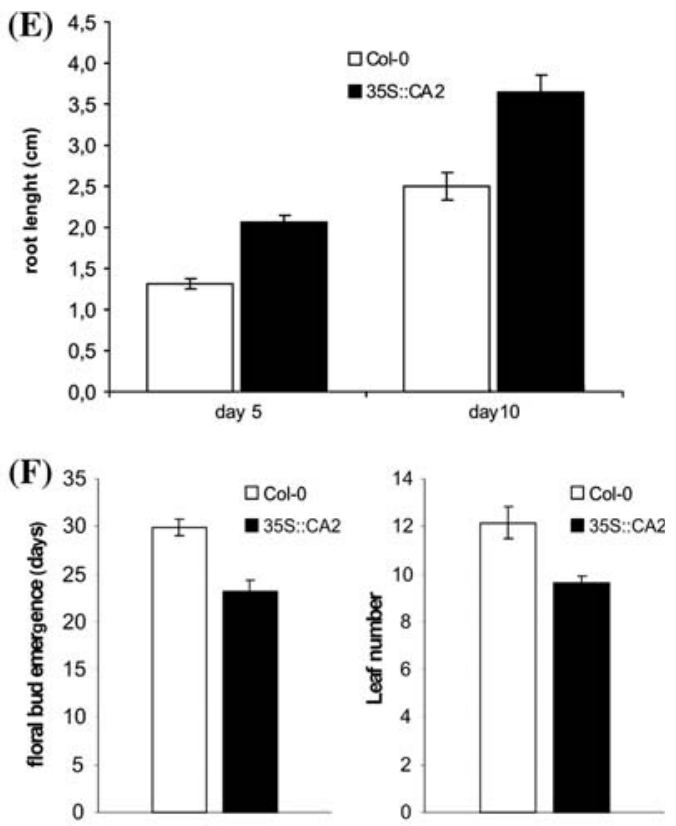

(G)

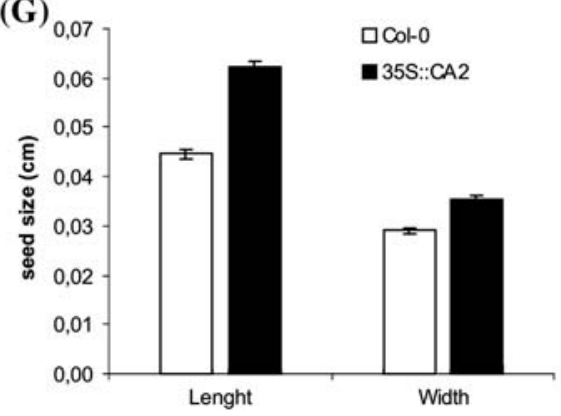

Fig. 2 Ectopic overexpression of $C A 2$ causes male sterility in Arabidopsis thaliana. A-B Control and transgenic adult plant growing in soil. A great proportion of $35 \mathrm{~S}: \mathrm{CA} 2$ plants shows a male sterile phenotype as a remarkable feature. Aborted fruits can be observed ( $b$, inset). C-D After anthesis, pollen grains are not released from anthers in $35 \mathrm{~S}:: \mathrm{CA} 2$ background compared to wild type Col-0 plant. E Plate grown $35 \mathrm{~S}:$ :CA2 seedlings show an increased root length compared to

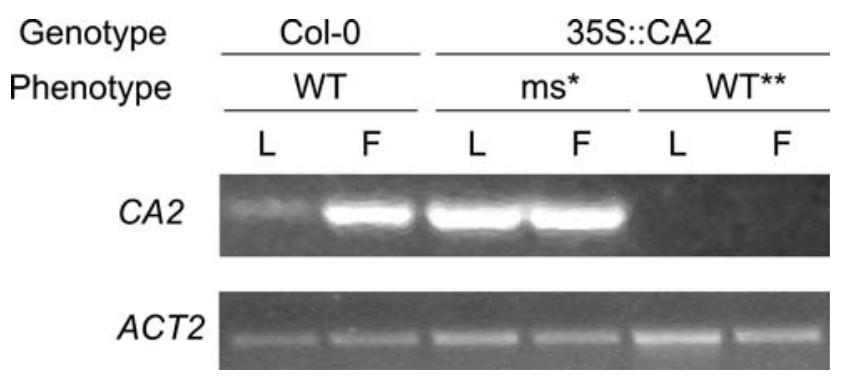

Fig. 3 Male sterility is correlated with ectopic overexpression of $C A 2$ gene. RT-PCR. Total RNA from leaf and flower was extracted. Using specific primers, a cDNA fragment corresponding to $C A 2$ mRNA was amplified by 40 cycles and separated by electrophoresis on agarose gels. Samples containing Sybr SAFE (Invitrogen) were visualized. ACTIN 2 gene is shown as control. Differential expression of $C A 2$ gene in leaf (L) and flower (F) of wild type and 35S::CA2 plants showing male sterile $(*)$ or wild type $(* *)$ phenotypes
Col-0 seedlings. F 35S::CA2 plants growing in soil presented an earlyflowering phenotype, flowering both earlier in time and with a lower number of rosette leaves. G The CA2 overexpressing plants eventually produce some fertile flowers and generate a reduced number of seeds, which are larger in size compared to the Col-0 seeds. In all cases results are expressed as mean $\pm \mathrm{SD}(n=10$ seedlings from at least three independent experiments)

development, the appearance of the endothecium changes just before the secondary thickening occurs, because endothecial cells undergo an expansion mainly toward the locule, which is finally restricted by the secondary wall. In contrast, in 35S::CA2 plants, endothecial cells do not expand and do not have a secondary wall, which leads to endothecium collapse at the end of development. In wild type, while endothecial cell expansion is taking place, epidermal cells are much reduced mainly by dehydratation. Conversely, epidermis of $35 \mathrm{~S}:: \mathrm{CA} 2$ anthers does not undergo any visible dehydratation process and surrounds completely the anther (Fig. 4 bottom). These differences mean that stomium cannot be opened as in the wild type and anthers fail to open (Fig. 4A bottom). In conclusion, ectopic expression of CA2 causes male sterility as a result of a failure of anther dehiscence. 
Fig. 4 Phenotypic and

histological examination of wild type and 35S::CA2 anthers.

A Transverse sections of wild type (Col-0) and overexpressing plants (35S::CA2) at three

different developmental stages

(8, 11, and 13 or anthesis). Str stomium region; $E n$

endothecium; $E$ epidermis;

$T$ tapetum; $F b$ Fibrous band $S m$

septum; St stomium. B Anther

of wild type (Col-0) and

overexpressing plants

(35S::CA2). Anthers of

transgenic plant are unable to

release pollen grains
(A)

Col-0
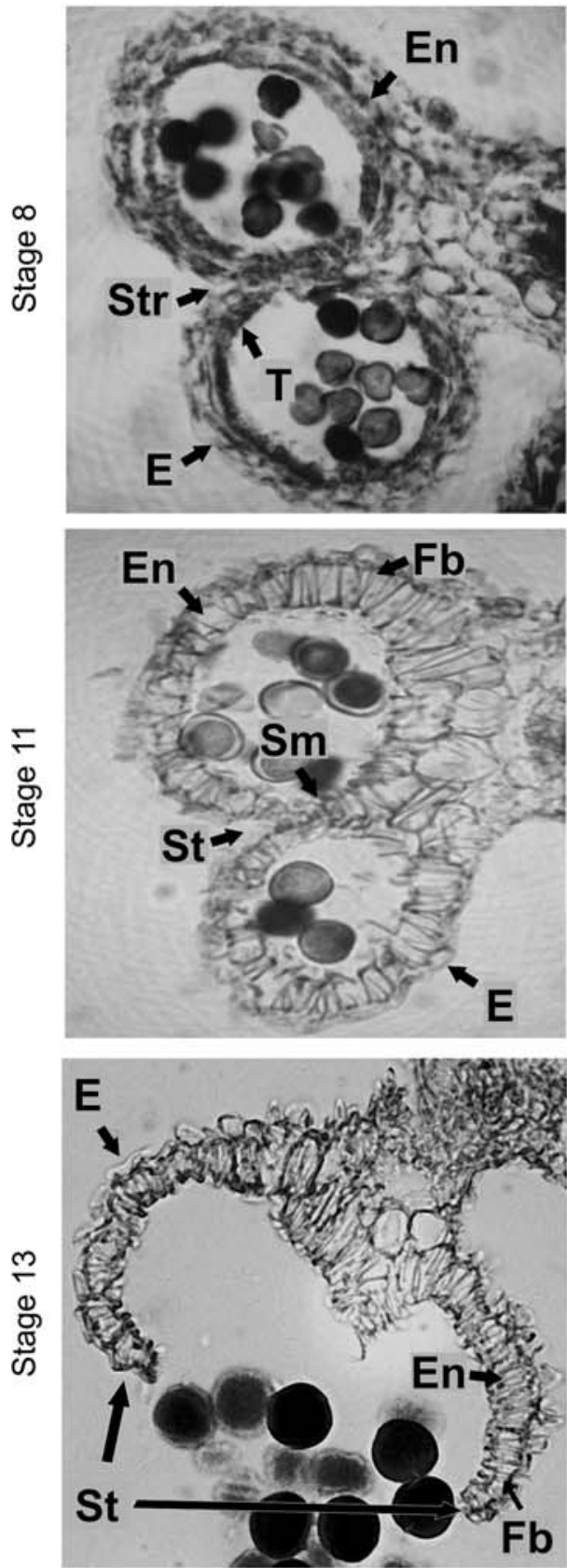

(B)

Col-0

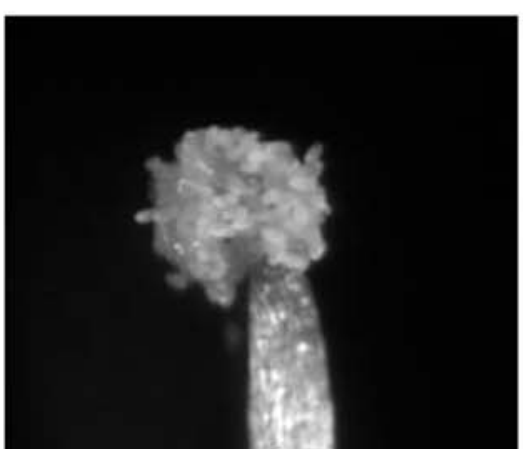

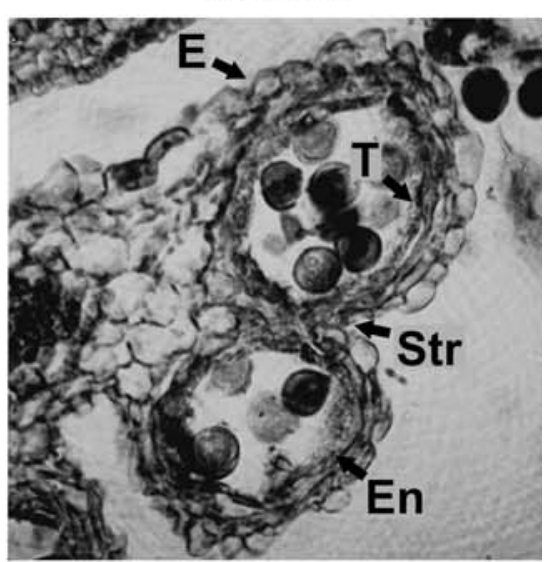
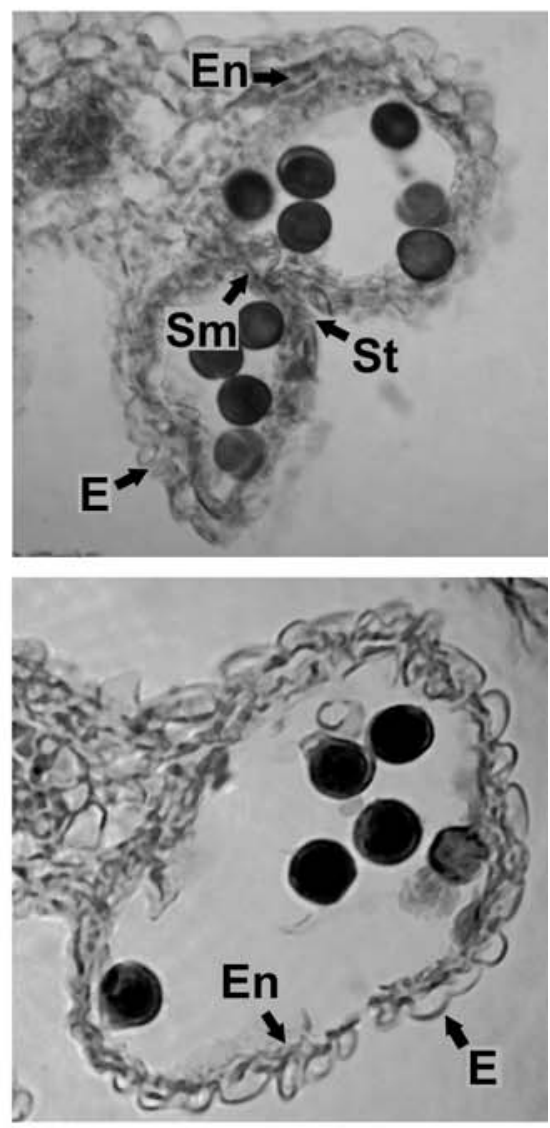

35S::CA2

35S::CA2

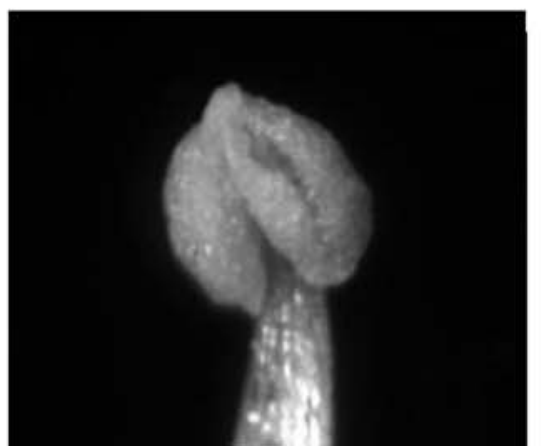


The first stages of anther development were normalincluding the tapetal cell layer development and degeneration, which is important for pollen development, and pollen grains appear to be normal when observed under optical microscopy. Because of these observations, we speculated that pollen function was not affected by ectopic expression of CA2. To test this, pollen grains were released manually from $\mathrm{ms}$ anthers and subjected to Alexander staining or pollen tube growth assay (data not shown). Both kind of assays demonstrated that pollen grains from 35S::CA2 plants are nearly normal indicating that male sterility was due to failure in anther opening rather than pollen dysfunction. Indeed, 35S::CA2 plants produce viable pollen which can fertilize when released mechanically from the anthers. No changes in female fertility are detected, because full seed set can be obtained by crossing the male sterile $35 \mathrm{~S}:$ :CA2 gynoecium with pollen from wild-type plants. In both cases a segregation $1: 1 \mathrm{~ms} /$ wild type was obtained.

CA2 protein is ectopically expressed in $35 \mathrm{~S}: \mathrm{CA} 2$ plants

Using anti-CA antibody, which recognizes all five members of the CA family, a 2-3 fold increase of CA2 protein in leaves was detected respect to that in the wild type (Fig. 5A, B). However, similar levels were detected in flowers consistent with RT-PCR analyses, where CA2 transcript is up-regulated in leaves but show similar levels in flowers (Fig. 5C). Nevertheless, the expression pattern changed in transgenic anthers as detected using anti-CA2 specific antibody in immuno-histochemical analyses on anthers of both, wild type and 35S::CA2 plants (Fig. 5D). Since the strong $35 \mathrm{~S}$ CaMV promoter used for the generation of the transgenic plants differs in activity with respect to the endogenous $\mathrm{CA} 2$ promoter, an ectopic CA2 expression is caused, particularly in the anther endothecium. Indeed, the male sterile phenotype correlates with ectopic expression of the protein. CA2 encoded by the transgene is most likely able to be imported into mitochondria because in 35S::CA2-GFP plants, fluorescent protein was detected in mitochondria (Parisi et al. 2004). The phenotype of these latter plants is similar to $35 \mathrm{~S}:$ :CA2 plants.

In order to evaluate the expression of other $\gamma C A$ genes, semiquantitative RT-PCR analyses were performed. While $C A 1$ and $C A L 1$ transcripts are not affected, CA3 and CAL2 transcript levels are increased only in leaves, following the expression of CA2 mRNA, suggesting a close relation between these three genes (Fig. 5C). Indeed, immunoblotting analyses using anti-CA antibody revealed increased levels of other proteins cross-reacting with this antibody most likely corresponding to CA3 and CAL2 proteins (Fig. 5A; Perales et al. 2005) which is consistent with RT-PCR analyses.

35S::CA2 plants show defective respiration

To investigate whether over-expression of CA2 affects respiration in plants, oxygen consumption was measured in leaves of 35S::CA2, ca2 null mutant and wild type plants. As shown in Fig. 6, 35S::CA2 plants show nearly equivalent oxygen consumption rates with rotenone (which specifically inhibits complex I) or control water, in contrast to the normal $50 \%$ inhibition by rotenone seen in wild type plants. These results indicated that respiration was mainly due to alternative pathways and suggesting that complex I function was affected in vivo. Potassium cyanide inhibits respiration of both, wild type and ms plants. The ca2 null mutant plants, which contain $80 \%$ reduction of complex I levels but exhibit a normal phenotype (Perales et al. 2005) present respiration features similar to ms plants, suggesting that male sterility observed in $35 \mathrm{~S}$ ::CA2 plants could not only be due to defects in respiration.

\section{S::CA2 anthers present no lignin deposition}

Male sterile phenotype of $35 \mathrm{~S}:$ :CA2 plants was not due to pollen dysfunction but a failure in anther dehiscence. Anthers of the transgenic plants show a lack of secondary thickening of cell wall, which is clearly observed by microscopic examination. This failure could be due to defects in lignin deposition during the last steps of anther development. To test this hypothesis, male sterile and wild type anthers stained with acridine orange/ethidium bromide (AO/EtBr) were examined using a confocal microscope (lignin polymer stains in red color with $\mathrm{EtBr}$, while $\mathrm{AO}$ dyes in green primary cell walls). As shown in Fig. 7, while a strong red staining is seen in the wild type anthers (Fig. 7B, C), 35S::CA2 anthers are not stained by EtBr (Fig. 7E, F) indicating a great reduction of lignin deposition and, most likely, accounts for the lack of secondary thickening. This could be the reason these anthers are unable to open. It is interesting to note that lignin content appears to be similar in the anther filaments of wild type as well as in $35 \mathrm{~S}:$ :CA2 plants.

ROS production is reduced in $35 \mathrm{~S}:$ :CA2 plants

Complex I is known to be the major site of ROS production in plant mitochondria (Møller et al. 2007 and references therein). Altered complex I function therefore might change the ROS content in anthers. At stage 10 of anther development, peroxides are normally detected mainly in a fine cell layer surrounding anther locules. This peroxide accumulation precedes and is related to programmed cell 

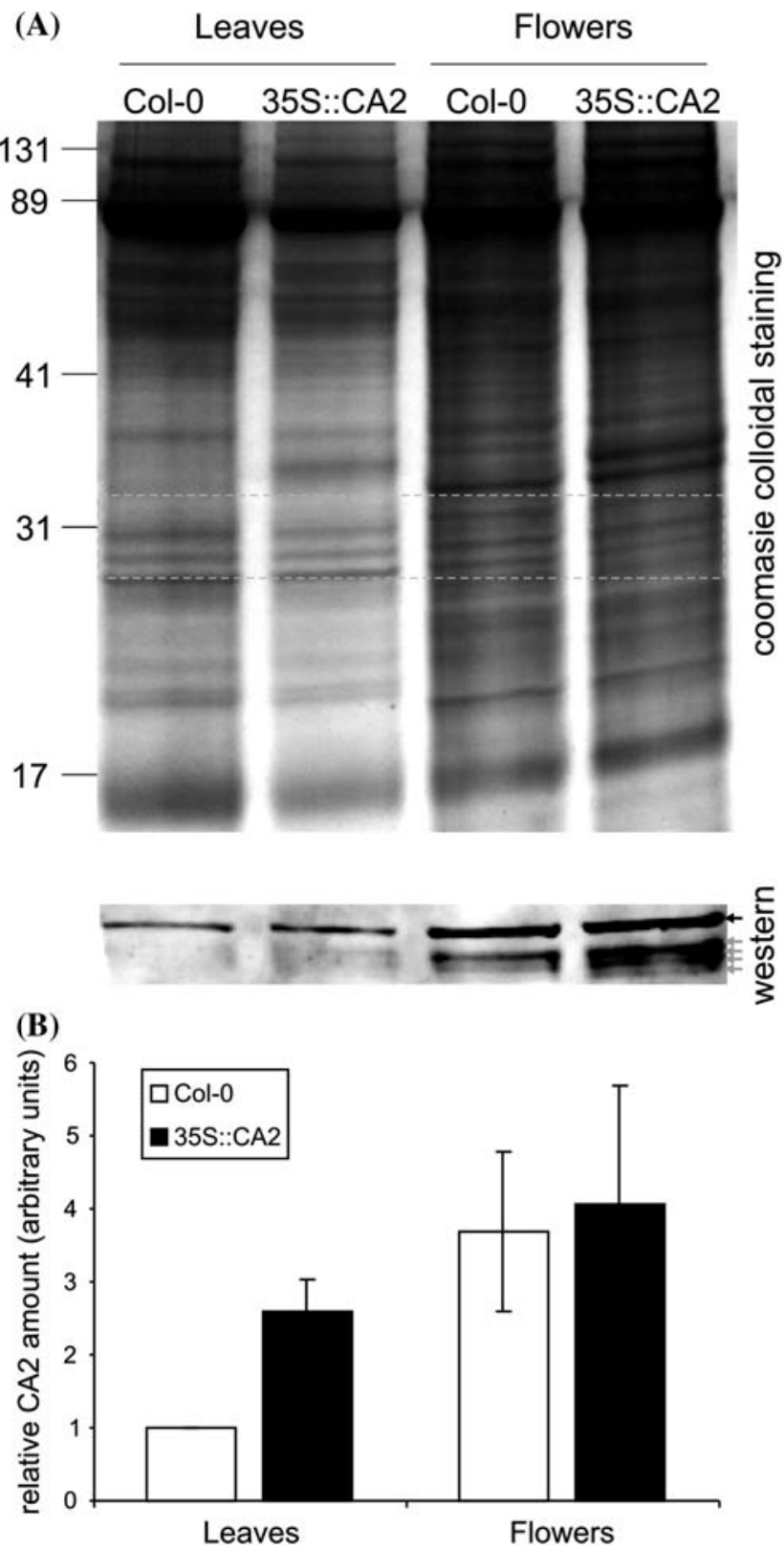

Fig. 5 CA2 is ectopically expressed in 35S::CA2 anthers. A Total protein from leaves and flowers of wild type (Col-0) and 35S::CA2 leaves and flowers were extracted, separated by a $16 \%$ polyacrylamide gels and Coomasie stained (top) or blotted onto PVDF membranes. CA2 was immuno-detected using anti-CA antibody (Perales et al. 2005) and revealed with a fluorescent secondary anti rabbit (bottom). The molecular masses of standard proteins are given to the left of the Coomassie Blue-stained gel. The black arrow in the western blot shows CA2 band, while grey arrows correspond to the other four CA proteins. B Quantification of protein amounts was performed using image QuaNT software (GE, Healthcare). Proteins separated by tricine-SDS PAGE were transferred to PVDF membranes and incubated with anti-CA antibody. The higher molecular weight immuno-reactive band corresponding to CA2 protein was quantified. Lower molecular weight bands represent other member of
(C)

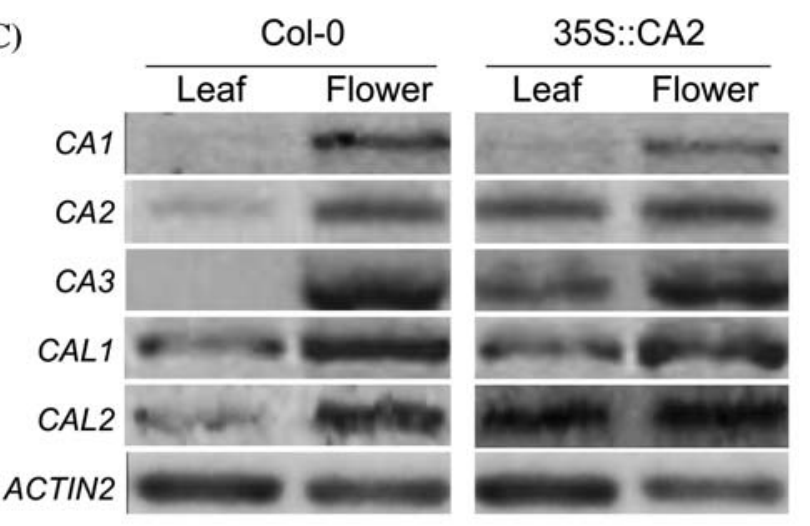

(D)
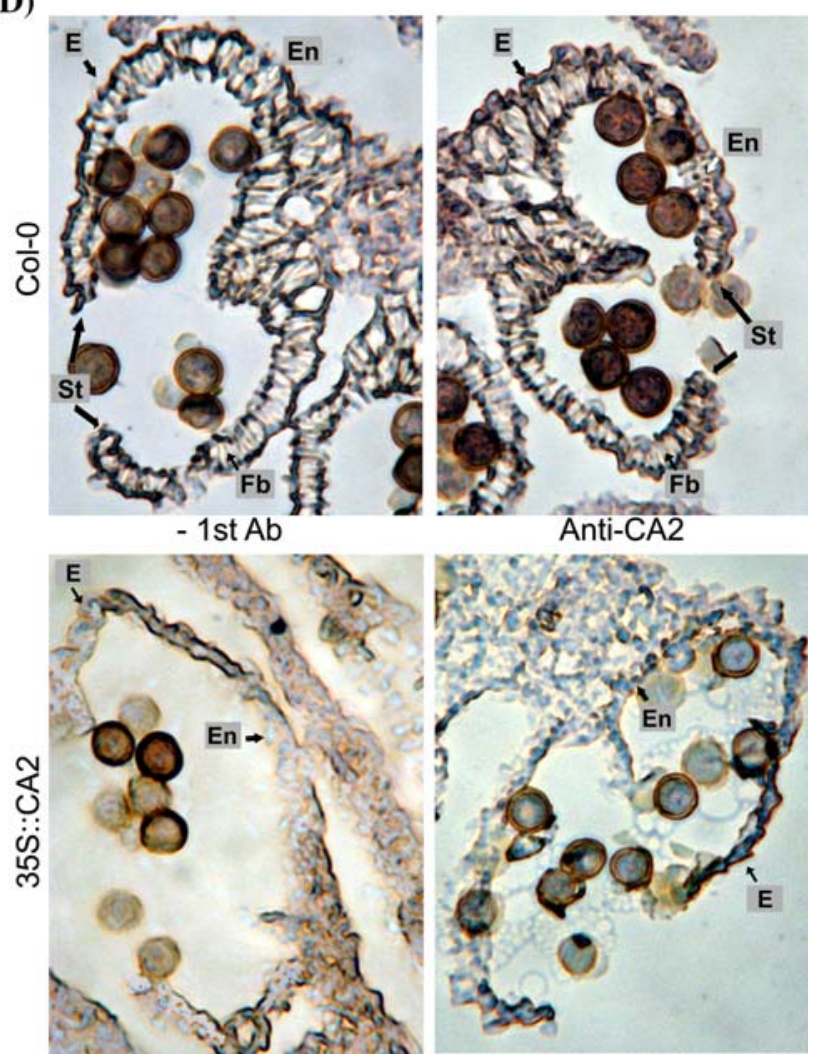

the gamma CA family cross reacting with this antibody (Perales et al. 2005). Values represent mean and error bars represent SD from three independent experiments). C Semiquantitative RT-PCR. Total RNA from leaf and flower was extracted. Using specific primers, cDNA fragments corresponding to $C A 1, C A 2, C A 3, C A L 1$, and $C A L 2 \mathrm{mRNA}$ were amplified by 16 cycles (exponential phase) and separated by electrophoresis on agarose gels. Samples containing Sybr Gold were quantified. ACTIN 2 gene is shown as loading control. D Anthers from wild type and 35S::CA2 plants were embedded in paraplast, deparaffined and rehydrated as explained in "Materials and methods". Sections were incubated with anti-CA2 antibody, washed and incubated with alkaline phosphatase conjugated secondary antibody. Control sections were processed without anti-CA2 antiserum. Upper panel: wild type anthers, lower panel: $35 \mathrm{~S}:: \mathrm{CA} 2$ anthers 


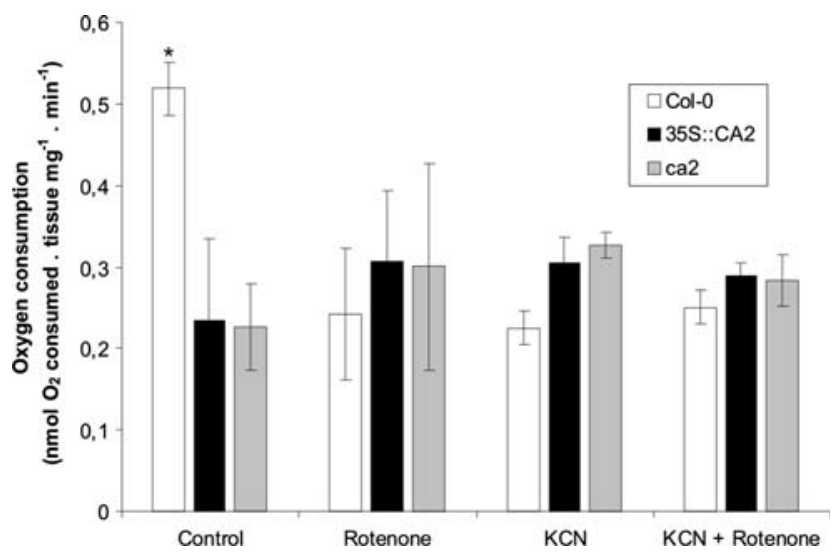

Fig. 6 35S::CA2 plants show reduced respiration. Oxygen consumption was measured in detached leaves from wild type (Col-0), 35S::CA2 and ca2 null mutant plants after different treatments as indicated in "Materials and methods". Water (control), rotenone (complex I specific inhibitor), Potassium cyanide (KCN-Complex IV specific inhibitor) and rotenone $+\mathrm{KCN}$. Values represent mean and error bars represent SD $(n=20)$ from three independent experiments. Statistically significant differences respect to Col-0 samples $(P<0.05)$ are marked with $*(n=20)$

death of anther wall cells (Ren et al. 2002). It was also demonstrated that high peroxide production is critical for $\mathrm{H}_{2} \mathrm{O}_{2}$-dependent lignin polymerization and deposition (Kärkönen and Fry 2006), which leads to secondary thickening. This in turn becomes important to drive forces needed to anther dehiscence. Stage 10 anthers of wild type, ca2 null mutant and $35 \mathrm{~S}:: \mathrm{CA} 2$ plants were subjected to DAB staining to detect $\mathrm{H}_{2} \mathrm{O}_{2}$ content as a dark brown precipitate. Wild type and ca2 mutant anthers show a normal brown staining (arrowed in Fig. 8) In contrast, DAB staining of ms anther at the same stage is nearly undetectable, indicating a strong reduction in peroxide content from any source (Fig. 8). Similar results were obtained using probes to detect other ROS (i.e., Nitro Blue Tetrazolium-NBT for superoxide detection). It was then concluded that normal ROS burst prior anther dehiscence is almost absent when CA2 is ectopically expressed.

Ascorbic acid content is reduced in $35 \mathrm{~S}:: \mathrm{CA} 2$ plants

Since ms anthers show low ROS concentration and defects in respiration, it was thought that an increase in anti-oxidant molecules could be responsible for this decrease. Ascorbic acid (AsA) very much contributes to the detoxification of ROS (Bartoli et al. 2000; Conklin 2001; Conklin and Barth 2004). Bartoli et al. (2006) suggested that the mitochondrial electron transport chain exerts co-ordinated control over redox pathways involving AsA and alternative oxidase (AOX) capacity.

Therefore, content and redox state of ascorbate and glutathione, the major soluble antioxidants of plant cells, were compared between leaves and flowers from wild type and $35 \mathrm{~S}:: \mathrm{CA} 2$ plants. Interestingly, the last enzyme in the ascorbate biosynthetic pathway is a mitochondrial protein, which forms part of a special complex I type which is smaller than the main form of this respiratory complex (Millar et al. 2003).

Surprisingly, leaves, as well as flowers of $35 \mathrm{~S}:: \mathrm{CA} 2$ and ca2 null mutant plants contain reduced total ascorbate contents compared to wild type organs (Fig. 9A and data not shown). The proportion between oxidized and reduced forms is similar among all three genetic backgrounds suggesting that the redox state was unaffected. On the other hand, the total glutathione content was nearly similar in all plants analyzed, although oxidized GSH levels were slightly increased in $35 \mathrm{~S}:: \mathrm{CA} 2$ leaves compared to the wild
Fig. 7 35S::CA2 anthers show low lignin content. Flowers from wild type (Col-0) and 35S:CA2 plants were stained with Acrydine Orange (Green fluorescence for cell walls) and Ethidium Bromide (Red fluorescence when binds lignin). Anthers were then analyzed by confocal microcopy as described in "Materials and methods". Yellow colored represents the co-localization of lignin and cell walls in merge pictures $(n=10)$

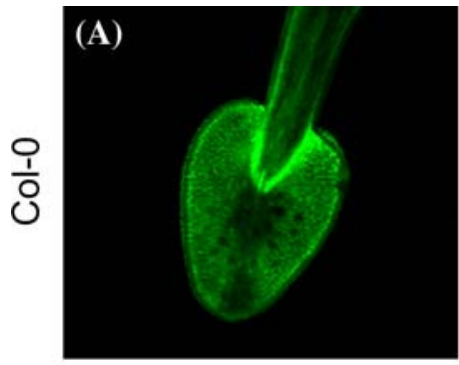

Acridine orange

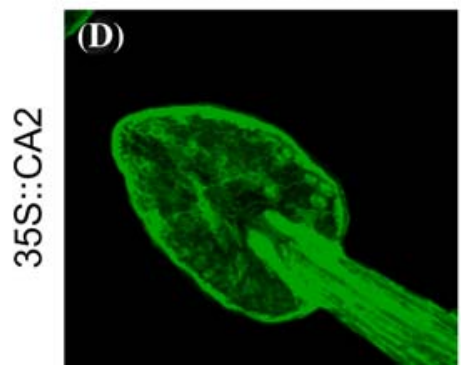

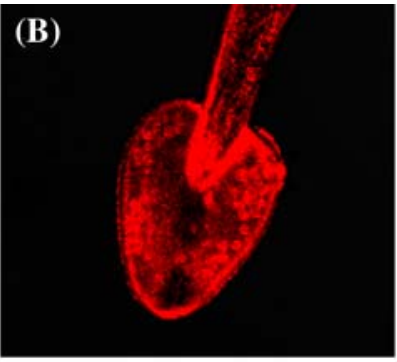

Ethidium bromide

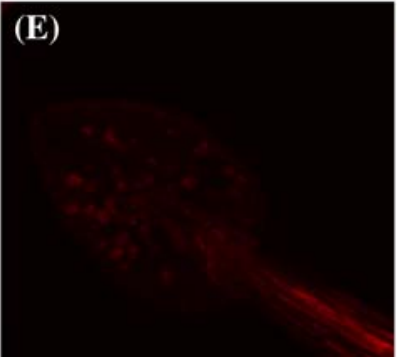

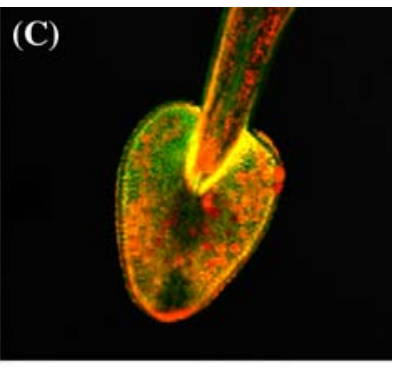

Merge

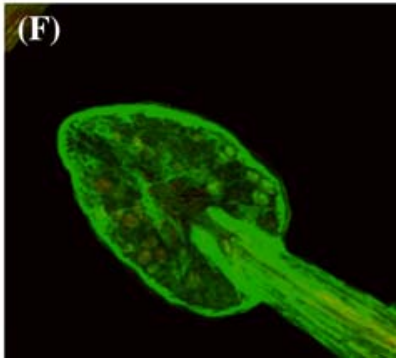



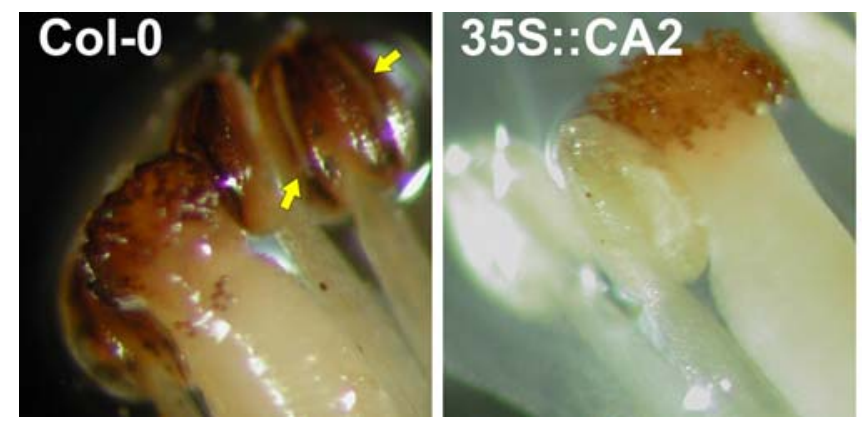

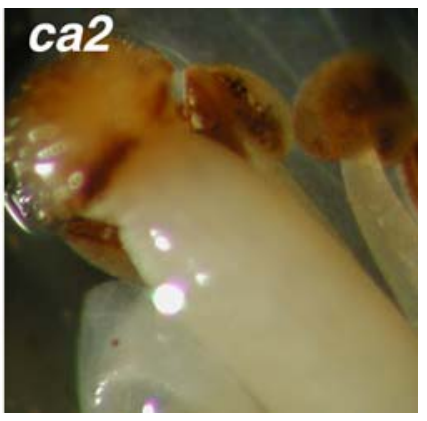

Fig. 8 Anthers from 35S::CA2 plants show low peroxide levels. Flowers from wild type (Col-0), 35S:CA2 and ca2 null mutant plants were incubated with $3,3^{\prime}$-diaminobenzidine $(\mathrm{DAB})$ for $2 \mathrm{~h}$ at $25^{\circ} \mathrm{C}$.

type (Fig. 9B and data not shown). AOX expression was also similar among these plants (data not shown). Thus, the differences observed in anti-oxidant content can not account for the strong reduction of ROS seen only in $35 \mathrm{~S}:: \mathrm{CA} 2$ plants. It is therefore concluded that ROS formation in anthers is affected most likely by a defect in complex I function when CA2 is ectopically expressed.

\section{Discussion}

In this report, we have studied the physiological and biochemical consequences of the ectopic over expression of mitochondrial gamma CA2 protein, a plant-specific subunit of respiratory chain complex I located at the CA domain of the complex (Sunderhaus et al. 2006). Ectopic expression of CA2 causes mainly male sterile phenotype because anthers fail to open. Pollen grains are completely fertile but they remain locked into indehiscent anthers due to the lack of secondary thickening of endothecium. This perturbation avoids the occurrence of the shearing forces required to open anthers through the stomium. Although 35S::CA2 plants show respiratory defects similar to $c a 2$ null mutant plants, these features are consequence of different defects. The ca2 mutants show a strong decrease in Complex I $(\sim 80 \%)$ but a normal ROS production in anthers. This implies that remaining 20\% Complex I or the particular configuration of $c a 2$ respiratory chain is able to sustain normal vegetative growth and normal pollen development. Moreover, in mutant background, enough ROS could be produced to sustain, among other processes, lignin polymerization in the anthers, leading to normal anther dehiscence and consequently, fertile plants. 35S::CA2 plants in contrast, show defects in Complex I function and a dramatic decrease in ROS content (particularly superoxides and peroxides) production in anthers just before dehiscence stage. This strong reduction in ROS content is most likely related to the failure in $\mathrm{H}_{2} \mathrm{O}_{2}$-dependent lignin polymerization and deposition seen in $35 \mathrm{~S}:: \mathrm{CA} 2$ anthers
Images were taken with a binocular after decoloration with ethanol. $\mathrm{DAB}$ oxidized by peroxide is detected as a dark brown precipitate. Arrows indicate the fine cell layer surrounding anther locules

that lack secondary thickening. Although several attempts were made, it was not possible to establish a cell suspension culture derived from $35 \mathrm{~S}:: \mathrm{CA} 2$ or $35 \mathrm{~S}:: \mathrm{CA} 2-\mathrm{FLAG}$ plants that over-express the protein. In consequence, the intramitochondrial location of extra CA2 protein remains uncertain. Because CAs are thought to form heterotrimers, it is at least possible to assert that extra CA2 protein form trimers with CA3 and CAL2 proteins whose transcript levels are increased in 35S::CA2 leaves. This possibility should be further investigated.

Lack of secondary thickening in the anther endothecium and dehiscence

A similar phenotype, as the one described for the ectopic expression of CA2 was recently described for the A. thaliana ms 35 mutant (Yang et al. 2007). This mutant impairs transcription of MYB26/MALE STERILE35 (MS35) gene, which is critical for the development of secondary thickening in the anther endothecium and subsequent dehiscence. MYB26 is localized to the nucleus and regulates endothecial development and secondary thickening in a cell-specific manner in the anther but not in other tissues of the plant. MYB26 regulates a certain number of genes linked to secondary thickening (Yang et al. 2007). Therefore, MYB26 appears to function in a regulatory pathway involved in determining endothecial cell development within the anther and acts upstream of the lignin biosynthesis pathway. Wall thickenings are not formed in the ms35 endothecium, resulting in the endothecial cells becoming flattened and distorted (Dawson et al. 1999). The lack of thickening means that the outward bending of the anther wall fails to occur, the endothecial cells collapse, and the anther fails to open. This phenotype is exactly the same as the one observed when CA2 is ectopically expressed. While MYB26 acts upstream of the lignin biosynthesis pathway, ectopic CA2 is proposed to impair the final step of lignin polymerization and deposition, specifically in the anther endothecium, via an important reduction 

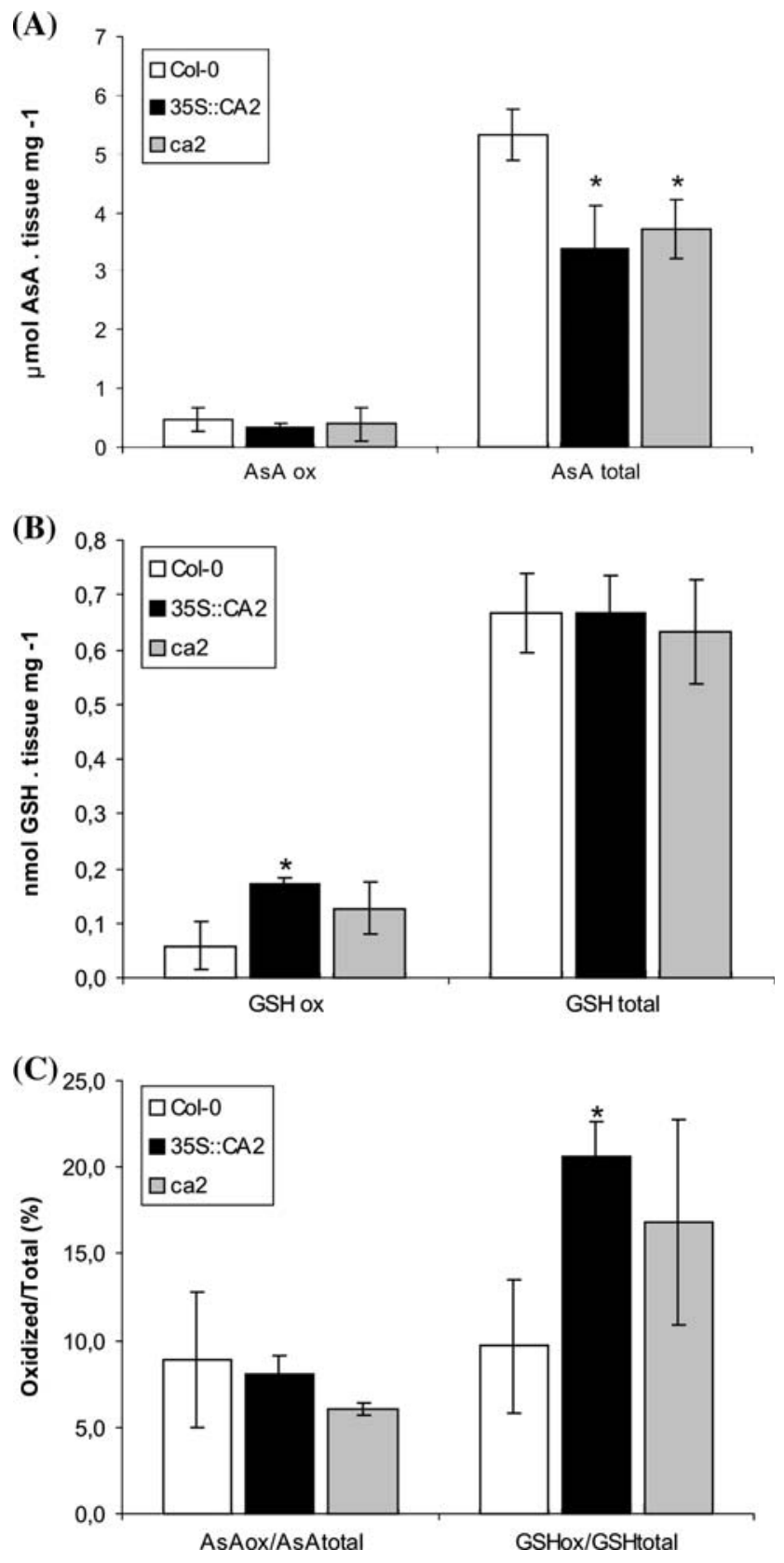

Fig. 9 35S::CA2 plants show altered anti oxidant levels. Oxidized and total anti-oxidant [ascorbic acid (AsA) and glutathione (GSH)] levels were measured in detached leaves of wild type (Col-0), 35S::CA2 and ca2 null mutant plants as described in "Materials and methods". A Oxidized (AsA ox) and total (AsA total) Ascorbic Acid content. B Oxidized (GSH ox) and total (GSH total) Glutathione content. C Oxidized/total ratio was determined for Ascorbic Acid and Glutathione. Statistically significant differences respect to Col-0 samples $(P<0.05)$ are marked with $*(n=20)$

of hydrogen peroxide production. In addition, the lower ascorbate levels in 35S::CA2 plants may be the result of a downregulation of its synthesis as a consequence of a reduced ROS accumulation. However, lignification pattern in the vascular tissue of the anthers, stems, and leaves is the same in wild-type, ms35/myb26 and 35S::CA2 plants (Yang et al. 2007 and this work). As it was previously mentioned, lignin content seems to be unaffected in the anther filaments (Fig. 7) suggesting that lignin synthesis, polymerization and deposition in the vascular tissue follow a different mechanism.

Lignin polymerization dependent on peroxide levels in anthers

Lignin is an important structural component of the cell wall of certain supportive and water-conducting cells. Lignification is the process of forming the collective of phenylpropanoid macromolecules termed lignin. It has been recognized for 50 years now that lignin is a polymeric material composed of phenylpropanoid units derived from three cinnamyl alcohols (monolignols): p-coumaryl, coniferyl, and sinapyl alcohols. Lignin polymerisation, the formation of the lignin macromolecule, is thought to result from oxidative (radical-mediated) coupling between a monolignol and the growing oligomer/polymer. The final polymerisation steps of lignin biosynthesis take place after the activation of monolignols to free radicals by the action of peroxidase $+\mathrm{H}_{2} \mathrm{O}_{2}$ and/or laccase $+\mathrm{O}_{2}$ followed by non-enzymic coupling of monolignol radicals to form the polymer, lignin (Boerjan et al. 2003; Ralph et al. 2004). Karlsson et al. (2005) presented data suggesting that $\mathrm{H}_{2} \mathrm{O}_{2}$ is required for the development and lignification of the secondary walls of tracheary elements (TEs) in the Zinnia cell-culture system. The addition of $\mathrm{H}_{2} \mathrm{O}_{2}$ scavengers, such as ascorbate, catalase, and reduced glutathione to cell cultures at the time of tracheary element initiation reduced the amount of lignin and the development of the secondary cell walls. Therefore, lignin polymerisation and subsequent deposition in cell wall were suggested to be dependent on hydrogen peroxide levels in vivo. Oxidative coupling of ferulates to form dehydrodiferulates in primary cell walls (Fry 2000) and of tyrosine residues of cell wall glycoproteins to form di-isodityrosine and related products were suggested to be mediated by peroxidases (Kerr and Fry 2004; Fry 2004; Encina and Fry 2005). All these crosslinking reactions taking place in the cell wall are likely to lead to the restriction of cell elongation. In this context, it is interesting to note that a negative correlation was found between apoplastic $\mathrm{H}_{2} \mathrm{O}_{2}$ levels and the growth rate of pine hypocotyls (Pedreira et al. 2004; Kärkönen and Fry 2006). It has been shown that NADPH oxidase activation, which generates superoxide and consequently hydrogen peroxide may contribute to lignin polymerization (Kawasaki et al. 2006). Our data are in agreement with these previous observations concerning lignin polymerization and deposition, which mainly come from investigations of wood plants but should also be valid in A. thaliana. Indeed a dramatic 
reduction in hydrogen peroxide formation from any source was observed in anthers of Arabidopsis plants ectopically expressing CA2. Thus, inhibition of $\mathrm{H}_{2} \mathrm{O}_{2}$-dependent lignin polymerization and deposition specifically in anthers' endothecium could take place.

What could be the relationship between mitochondrial defects and apoplastic ROS formation by a plasma membrane NADPH oxidase? In humans, a conserved signalling cascade involving mitochondrial ROS production and $\mathrm{Ca}^{2+}$ (as messengers) followed by activation of NADPH oxidase (NOX1) through the Rac1 pathway was described, which is crucial for the sustained accumulation of ROS and cell death (Lee et al. 2006). In plants, mitochondrial ROS have been postulated to represent second messengers (Gray et al. 2004) and a similar link involving plant Rac homologues and NADPH oxidase activation were reported (Torres and Dangl 2005; Kawasaki et al. 2006; Møller et al. 2007). Therefore, mitochondrial defects caused by overexpression of the CA2 protein, could eventually reduce ROS formation (as messenger) by complex I dysfunction. In this scenario, ROS formation by plasma membrane NADPH oxidase could be extremely decreased by lack of mitochondrial ROS signalling. This could then lead to the avoidance of lignin polymerisation, secondary thickening and consequently to the failure of anther opening. In 35S::CA2 leaves, ROS levels are not altered, suggesting other sources (mainly chloroplast) for ROS formation. Experimentally, we have shown both, undetectable ROS levels in anthers (from any source) and lack of lignin deposition in anther walls.

It is interesting to mention that a similar transformation experiment using $35 \mathrm{~S}:$ :CA1 construct leads to kanamycin resistant seedlings showing aborted growth that die 2-3 days after germination (A. Colaneri and E. Zabaleta, unpublished results). Although it could not be possible to perform any biochemical or physiological analysis, it is reasonable to think that lignin polymerization and deposition were fully affected and growth would be then prohibited.

\section{Predicted physiological role of At $\gamma \mathrm{CAs}$}

What could be the reason why ectopically expressed CA2 leads to such a drastic reduction in ROS content? Different hypotheses can be suggested. In animals, it was found that an alkalinization of the mitochondrial matrix increased ROS production by an over-reduction of the complex I (Andrukhiv et al. 2006). If matrix $\mathrm{pH}$ increases, the flow of electrons is retarded causing an increased reduction at the flavin site and consequently increased superoxide production which is rapidly converted into hydrogen peroxide. However, if complex I activity is affected, the flavin site could then be oxidized and ROS production would be reduced. In Drosophila, it was found that superoxide production from complex I following reverse electron flow was very sensitive to a small decrease in membrane potential; a $10 \mathrm{mV}$ drop in membrane potential decreased ROS production by $70 \%$ (Miwa and Brand 2003). Then, we could hypothesize that an abnormal increase in CA2 protein and most likely CA3 and CAL2 may lead to the formation of active extra trimers in a particular mitochondria (e.g., Endothecial mitochondria). These putative extra trimers could cause an abnormal acidification of the mitochondrial matrix, impairing complex I function, which in turn would cause a decrease in ROS production, resulting in a much lower steady-state level of ROS than was found in wild type anthers. These putative active trimers should then increase $\mathrm{HCO}_{3}{ }^{-}$levels and thus produce an acidification, which would also affect the electrochemical gradient across the inner mitochondrial membrane.

It is interesting to mention that overexpression of CA III in NIH/3T3 cells caused a protection against peroxidemediated apoptosis (Räisänen et al. 1999). CA III is a cytosolic enzyme highly expressed in skeletal muscle in rats. It was demonstrated that in skeletal muscle, CA III also exhibits a protective role against peroxide (Zimmerman et al. 2004). Thus, the complex I integrated CAs could protect tissues against peroxides when its normal expression is high. For example, a high respiratory rate with a high ROS production, as observed in the tapetum, might need a high expression of CAs to avoid premature programmed cell death and allow a correct pollen development. However, CAs' expression should be low in the endothecium to permit ROS bursts and lignification necessary for shearing forces and anther dehiscence. This highlights the importance of tight regulation of mitochondrial functions in late anther development.

In conclusion, ectopic expression of CA2 causes functional problems to Complex $\mathrm{I}$ in tissues where CA2 expression is normally low (e.g., endothecium or leaves) that are related to intra-mitochondrial physiological conditions. Abnormal CA2 expression, and consequently CA3 and CAL2 expression causes a strong reduction in ROS production. Lack of ROS burst in anthers might impair lignin polymerization. This impairs secondary thickening in the anther endothecium and finally causes anthers indehiscence and male sterility.

Acknowledgments This work was supported in part by ANPCyT (13432 and 31669) (Argentina), DAAD (Germany), ECOS-Sud, (A06B03) (France-Argentina). FV and MVM (CONICET, Argentina) are doctoral fellows and this work is part of their doctoral theses.

\section{References}

Alber BE, Ferry JG (1994) A carbonic anhydrase from the archaeon Methanosarcina thermophila. Proc Natl Acad Sci USA 91:69096913. doi:10.1073/pnas.91.15.6909 
Andrukhiv A, Costa AD, West IC, Garlid KD (2006) Opening mitoKATP increases superoxide generation from complex I of the electron transport chain. Am J Physiol Heart Circ Physiol 291:2067-2074. doi:10.1152/ajpheart.00272.2006

Badger MR, Price GD (1994) The Role of carbonic anhydrase in photosynthesis. Annu Rev Plant Physiol Plant Mol Biol 45:369392. doi:10.1146/annurev.pp.45.060194.002101

Bartoli CG, Pastori GM, Foyer CH (2000) Ascorbate biosynthesis in mitochondria is linked to the electron transport chain between complexes III and IV. Plant Physiol 123:335-344. doi:10.1104/ pp.123.1.335

Bartoli CG, Yu J, Gómez F, Fernández L, McIntosh L, Foyer CH (2006) Inter-relationships between light and respiration in the control of ascorbic acid synthesis and accumulation in Arabidopsis thaliana leaves. J Exp Bot 57:1621-1631. doi:10.1093/ jxb/erl005

Bechtold N, Pelletier G (1998) In planta Agrobacterium-mediated transformation of adult Arabidopsis thaliana plants by vacuum infiltration. Methods Mol Biol 82:259-266

Boerjan W, Ralph J, Baucher M (2003) Lignin biosynthesis. Annu Rev Plant Biol 54:519-546. doi:10.1146/annurev.arplant.54. 031902.134938

Bonner L, Dickinson H (1989) Anther dehiscence in Lycopersicon esculentum mill. New Phytol 113:97-115. doi:10.1111/j.14698137.1989.tb02399.x

Braun HP, Zabaleta E (2007) Carbonic anhydrase subunits of the mitochondrial NADH dehydrogenase complex (complex I) in plants. Physiol Plant 129:114-122. doi:10.1111/j.1399-3054. 2006.00773.x

Clough SJ, Bent AF (1998) Floral dip: a simplified method for Agrobacterium-mediated transformation of Arabidopsis thaliana. Plant J 16:735-743. doi:10.1046/j.1365-313x.1998.00343.x

Conklin PL (2001) Recent advances in the role and biosynthesis of ascorbic acid in plants. Plant Cell Environ 24:383-394. doi: 10.1046/j.1365-3040.2001.00686.x

Conklin PL, Barth C (2004) Ascorbic acid, a familiar small molecule intertwined in the response of plants to ozone, pathogens, and the onset of senescence. Plant Cell Environ 27:959-971. doi: 10.1111/j.1365-3040.2004.01203.x

Dawson J, Wilson ZA, Briarty LG, Mulligan BJ (1993) Development of anthers and pollen in male sterile mutants of Arabidopsis thaliana. In: Bowman J (ed) Arabidopsis: an atlas of morphology. Springer, Berlin, pp 282-295

Dawson J, Sözen E, Vizir I, Van Waeyenberge S, Wilson ZA, Mulligan BJ (1999) Characterization and genetic mapping of a mutation (ms35) which prevents anther dehiscence in Arabidopsis thaliana by affecting secondary wall thickening in the endothecium. New Phytol 144:213-222. doi:10.1046/j.14698137.1999.00507.x

Encina A, Fry SC (2005) Oxidative coupling of a feruloylarabinoxylan trisaccharide (FAXX) in the walls of living maize cells requires endogenous hydrogen peroxide and is controlled by a low-Mr apoplastic inhibitor. Planta 223:77-89. doi: 10.1007/s00425-005-0033-y

Fry SC (2000) The growing plant cell wall: chemical and metabolic analysis, 2nd edn. Blackburn Press, Caldwell

Fry SC (2004) Oxidative coupling of tyrosine and ferulic acid residues, intra- and extra-protoplasmic occurrence, predominance of trimers and larger products, and possible role in interpolymeric cross-linking. Phytochem Rev 3:97-111. doi: 10.1023/B:PHYT.0000047808.74647.43

Goldberg R, Beals T, Sanders P (1993) Anther development: basic principles and practical applications. Plant Cell 5:1217-1229

Gray GR, Maxwell DP, Villarimo AR, McIntosh L (2004) Mitochondria/nuclear signaling of alternative oxidase gene expression occurs through distinct pathways involving organic acids and reactive oxygen species. Plant Cell Rep 23:497-503. doi:10.1007/s00299-004-0848-1

Griffith OW (1980) Determination of glutathione and glutathione disulfide using glutathione reductase and 2-vinylpyridine. Anal Biochem 106:207-212. doi:10.1016/0003-2697(80)90139-6

Hewett-Emmett D (2000) Evolution and distribution of the carbonic anhydrase gene families. EXS 2000:29-76

Kärkönen A, Fry SC (2006) Effect of ascorbate and its oxidation products on $\mathrm{H} 2 \mathrm{O} 2$ production in cell-suspension cultures of Picea abies and in the absence of cells. J Exp Bot 57:1633-1644. doi:10.1093/jxb/erj197

Karlsson M, Melzer M, Prokhorenko I, Johansson T, Wingsle G (2005) Hydrogen peroxide and expression of hipI-superoxide dismutase are associated with the development of secondary cell walls in Zinnia elegans. J Exp Bot 56:2085-2093. doi:10.1093/ jxb/eri207

Kawasaki T, Koita H, Nakatsubo T, Hasegawa K, Wakabayashi K, Takahashi H, Umemura K, Umezawa T, Shimamoto K (2006) Cinnamoyl-CoA reductase, a key enzyme in lignin biosynthesis, is an effector of small GTPase Rac in defense signaling in rice. Proc Natl Acad Sci USA 103:230-235. doi:10.1073/pnas.05 09875103

Keijzer C (1987) The processes of anther dehiscence and pollen dispersal. I. The opening mechanism of longitudinally dehiscing anthers. New Phytol 105:487-489. doi:10.1111/j.1469-8137. 1987.tb00886.x

Kerr EM, Fry SC (2004) Extracellular cross-linking of xylan and xyloglucan in maize cell-suspension cultures: the role of oxidative phenolic coupling. Planta 219:73-83. doi:10.1007/s00425004-1210-0

Lee SB, Bae IH, Bae YS, Um HD (2006) Link between mitochondria and NADPH oxidase 1 isozyme for the sustained production of reactive oxygen species and cell death. J Biol Chem 281:3622836235. doi:10.1074/jbc.M606702200

Meyerowitz E (1987) In situ hybridization to RNA in plant tissue. Plant Mol Biol Rep 5:242-250. doi:10.1007/BF02669719

Millar AH, Mittova V, Kiddle G, Heazlewood JL, Bartoli CG, Theodoulou FL, Foyer CH (2003) Control of ascorbate synthesis by respiration and its implications for stress responses. Plant Physiol 133:443-447. doi:10.1104/pp.103.028399

Miwa S, Brand MD (2003) Mitochondrial matrix reactive oxygen species production is very sensitive to mild uncoupling. Biochem Soc Trans 6:1300-1301. doi:10.1042/BST0311300

Møller IM, Jensen PE, Hansson A (2007) Oxidative modifications to cellular components in plants. Annu Rev Plant Biol 58:459-481. doi:10.1146/annurev.arplant.58.032806.103946

Neuhoff V, Stamm R, Pardowitz I, Arold N, Ehrhardt W, Taube D (1990) Essential problems in quantification of proteins following colloidal staining with coomassie brilliant blue dyes in polyacrylamide gels, and their solution. Electrophoresis 11:101-117. doi:10.1002/elps.1150110202

Otter T, Polle A (1994) The influence of apoplastic ascorbate on the activities of cell wall-associated peroxidase and NADH oxidase in needles of Norway spruce (Picea abies L.). Plant Cell Physiol 35:1231-1238

Parisi G, Perales M, Fornasari MS, Colaneri A, González-Schain N, Gómez-Casati D, Zimmermann S, Brennicke A, Araya A, Ferry JG, Echave J, Zabaleta E (2004) Gamma carbonic anhydrases in plant mitochondria. Plant Mol Biol 55:193-207. doi: 10.1007/s11103-004-0149-7

Pedreira J, Sanz N, Pena MJ, Sánchez M, Queijeiro E, Revilla G, Zarra I (2004) Role of apoplastic ascorbate and hydrogen peroxide in the control of cell growth in pine hypocotyls. Plant Cell Physiol 45:530-534. doi:10.1093/pcp/pch059

Perales M, Parisi G, Fornasari MS, Colaneri A, Villarreal F, González-Schain N, Echave J, Gómez-Casati D, Braun HP, 
Araya A, Zabaleta E (2004) Gamma carbonic anhydrase like complex interact with plant mitochondrial complex I. Plant Mol Biol 56:947-957. doi:10.1007/s11103-004-6324-Z

Perales M, Eubel H, Heinemeyer J, Colaneri A, Zabaleta E, Braun HP (2005) Disruption of a nuclear gene encoding a mitochondrial gamma carbonic anhydrase reduces complex I and supercomplex I + III2 levels and alters mitochondrial physiology in Arabidopsis. J Mol Biol 350:263-277. doi:10.1016/j.jmb.2005.04.062

Peters K, Dudkina NV, Jänsch L, Braun HP, Boekema EJ (2008) A structural investigation of complex I and I + III2 supercomplex from Zea mays at 11-13 A resolution: assignment of the carbonic anhydrase domain and evidence for structural heterogeneity within complex I. Biochim Biophys Acta 1777:84-93. doi:10.1016/j.bbabio.2007.10.012

Räisänen SR, Lehenkari P, Tasanen M, Rahkila P, Härkönen PL, Väänänen HK (1999) Carbonic anhydrase III protects cells from hydrogen peroxide-induced apoptosis. FASEB J 13:513-522

Ralph J, Lundquist K, Brunow G et al (2004) Lignins: natural polymers from oxidative coupling of 4-hydroxyphenylpropanoids. Phytochem Rev 3:29-60. doi:10.1023/B:PHYT.0000 047809.65444.a4

Ren D, Yang H, Zhang S (2002) Cell death mediated by MAPK is associated with hydrogen peroxide production in Arabidopsis. J Biol Chem 277:559-565

Ruzin SE (1999) Plant microtechnique and microscopy. Oxford University Press, Oxford, NY, p 323

Sambrook J, Russell D (2001) Molecular cloning, a laboratory manual, 3rd edn. Cold Spring Harbor Laboratory Press, Cold Spring Harbor

Sánchez M, Quiejeiro E, Revilla G, Zarra I (1997) Changes in ascorbic acid levels in apoplastic fluid during growth of pine hypocotyls. Effect on peroxidase activities associated with cell walls. Physiol Plant 101:815-820. doi:10.1111/j.1399-3054.1997.tb01068.x

Schägger H, von Jagow G (1987) Tricine-sodium dodecyl sulfatepolyacrylamide gel electrophoresis for the separation of proteins in the range from 1 to $100 \mathrm{kDa}$. Anal Biochem 166:368-379. doi:10.1016/0003-2697(87)90587-2
Smith KS, Jakubzick C, Whittam TS, Ferry JG (1999) Carbonic anhydrase is an ancient enzyme widespread in prokaryotes. Proc Natl Acad Sci USA 96:15184-15189. doi:10.1073/pnas.96. 26.15184

Sunderhaus S, Dudkina NV, Jänsch L, Klodmann J, Heinemeyer J, Perales M, Zabaleta E, Boekema EJ, Braun HP (2006) Carbonic anhydrase subunits form a matrix-exposed domain attached to the membrane arm of mitochondrial complex I in plants. J Biol Chem 281:6482-6488. doi:10.1074/jbc.M511542200

Takahama U (1993a) Redox state of ascorbic acid in the apoplast of stems of Kalanchoë daigremontiana. Physiol Plant 89:791-798. doi:10.1111/j.1399-3054.1993.tb05286.x

Takahama U (1993b) Regulation of peroxidase-dependent oxidation of phenolics by ascorbic acid: different effects of ascorbic acid on the oxidation of coniferyl alcohol by the apoplastic soluble and cell wall-bound peroxidases from epicotyls of Vigna angularis. Plant Cell Physiol 34:809-817

Torres MA, Dangl JL (2005) Functions of the respiratory burst oxidase in biotic interactions, abiotic stress and development. Curr Opin Plant Biol 8:397-403. doi:10.1016/j.pbi.2005.05.014

Yang C, Xu Z, Song J, Conner K, Barrena VG, Wilson ZA (2007) Arabidopsis MYB26/MALE STERILE35 regulates secondary thickening in the endothecium and is essential for Anther Dehiscence. Plant Cell 19:534-548. doi:10.1105/tpc.106.046391

Zabaleta E, Heiser V, Grohmann L, Brennicke A (1998) Promoters of nuclear-encoded respiratory chain complex I genes from Arabidopsis thaliana contain a region essential for anther/ pollen-specific expression. Plant J 15:49-59. doi:10.1046/j.1365313X.1998.00177.X

Zimmerman SA, Ferry JG (2008) The beta and gamma classes of carbonic anhydrase. Curr Pharm Des 14:716-721. doi:10.2174/ 138161208783877929

Zimmerman U, Wang P, Zhang X, Bogdanovich S, Forster R (2004) Anti-oxidative response of carbonic anhydrase III in skeletal muscle. IUBMB Life 56:343-347. doi:10.1080/1521-6540 400000850 